\title{
Free-piston linear generator and the development of a solid lubrication system
}

\author{
Dipl.-Ing. Roman Virsik, Dr.-Ing. Frank Rinderknecht, Prof. Dr.-Ing. Horst E. Friedrich \\ Institute of Vehicle Concepts \\ German Aerospace Center (DLR) \\ Stuttgart, Germany \\ roman.virsik@dlr.de, frank.rinderknecht@dlr.de, horst.friedrich@dlr.de
}

\begin{abstract}
The free piston linear generator is a new electromechanical generator. It converts chemical energy into electrical energy by means of a combustion process, a linear generator and a gas spring. Thereby the technology aims to have better properties than other electromechanical generators. Therefore this publication deals with the explanation of the concept, the characteristics of a free piston linear generator and one of the challenges in the development. In order to use a port scavenging the emission issue is the challenge and has to be solved. One possible solution is the use of solid lubricants to substitute motor oil. The development methodology and one aspect of the development will be explained.
\end{abstract}

Keywords- FPLG; Free-piston linear generator; dry; solid; lubrication; combustion

\section{INTRODUCTION}

Efficiency improvements in order to reduce the production of $\mathrm{CO} 2$ are required in all technical areas of life to limit the anticipated climate changes [1] to an extent sustainable for humanity. Current approaches in the field of transportation cover both the increase of efficiency of conventional drives and the development of alternative power trains e.g. hybrid, battery, fuel cell and range extender concepts, and combinations of these. The aim of every alternative power train design is to transform the stored energy into a kinetic energy with the greatest possible efficiency. In many concepts electrical energy is necessary in order to drive electric motors.

This requirement is met particularly well by a free piston linear generator. It is capable of transforming chemical energy into electrical energy by means of a combustion process. As explained in [2], the high degree of efficiency and its independence of the load level are inherent in the design of the free-piston linear generator. This is achieved by keeping the system frequency constant and adapting to the power demand by variation of the stroke and compression ratio. Furthermore, these system characteristics give the free-piston linear generator the possibility to be powered by both conventional fuels such as petrol, diesel and natural gas and by alternative fuels such as biofuel, synthetic fuel, hydrogen etc.

The development goal for the FPLG is to use a port scavenged central opposed piston combustion chamber in order to save space and reduce complexity. One of the main challenges in this area is to guarantee the piston lubrication. A solid lubrication system as possible solution is described in this paper.

\section{FREE-PISTON LINEAR GENERATOR SYSTEM}

In the field of free piston motors the free piston linear generator is a promising design. The system described in the following is developed at the German aerospace center (DLR). The proof of concept took place in Stuttgart at the end of 2012 [2]. It was demonstrated that the control of a free piston engine can be designed to allow robust operation even with large combustion variations [3].

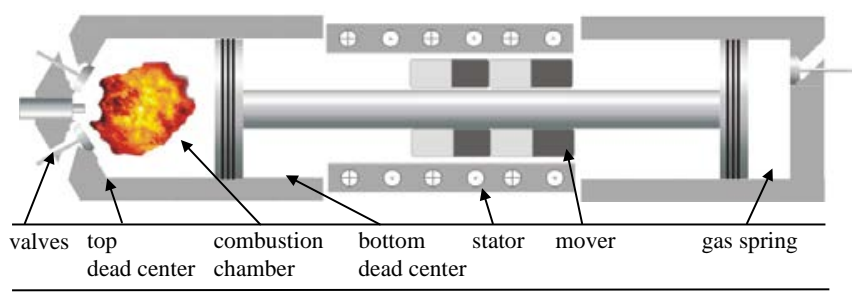

Fig. 1. Illustration of the principle of the free-piston linear generator

The free-piston linear generator module in figure 1 is used to explain the principle consisting of a piston rod connected with a piston on either side, cylinders around the pistons and a linear generator. At one end the cylinder forms the combustion chamber which is powered by a liquid or gaseous energy carrier. The gas exchange of the combustion chamber is controlled by valves in the cylinder head. The opposite 
cylinder creates an adjustable gas spring. The spring rate of the gas spring is adjusted by means of regulating the air mass in the cylinder.

The linear generator is positioned between the two cylinders. Its mover is mounted on the piston rod. The mover consists of permanent magnets glued into a plastic matrix and additionally secured by a fibre-glass reinforced bandage. Stators with integrated generator windings and a cooling system enclose the mover and complete the linear generator.

The load cycle begins with the combustion piston at the top dead center (TDC). The chamber is filled with a compressed, flammable mixture previously introduced into the combustion chamber which is ignited by a spark plug. The two pistons, the rod and the mover move towards the bottom dead center (BDC, direction of gas spring). The motion of mover and its magnets induces a voltage in the coils of the stator which drives a corresponding electric current. About half of the energy released in the combustion is converted during the movement from TDC to BDC by the linear generator. The other half is stored in the gas spring and extracted on the return stroke (BDC to TDC). While the gas spring is compressed (the combustion piston is at its BDC), the combustion chamber is actively scavenged with charged, fresh air. After injection of fuel the mixture is compressed and as the double piston system arrives at the TDC, the next load cycle can begin. The variation of the output power can be achieved by adjustment of the inlet pressure and injection period in combination with the stroke. Thereby the stroke is controlled by the air mass in the gas spring. The mechanical frequency of the double piston system only varies slightly between multiple operating points.

\section{POTENTIALS OF THE FPLG}

As the FPLG has no crankshaft the compression ratio is adjustable. An appropriate fuel supply system therefore would allow many types of fuel (petrol, diesel, natural gas, sun fuel, synthetic fuel, hydrogen, etc.). The fuels can be used without any constructional changes in the combustion unit, as the adaption of the compression ratio is design inherent. Thus the combustion takes place at the maximum compression ratio of the fuel, allowing the highest possible efficiency. The system operates with petrol and peak pressures of 80 bar in SIcombustion mode (SI - spark plug ignition) and over 100 bar in HCCI-combustion mode (HCCI - Homogeneous Charge Compression Ignition). Tests with other fuels will take place in near future.

To achieve a full mass compensation, two synchronized piston units are needed. An advantage of the FPLG is the freedom of alignment. There are many ways to connect the FPLG subsystems (Combustion unit, linear generator, gas spring, auxiliaries). The whole system can be built to fit under the trunk compartment or into a transmission tunnel. All possibilities only need a height of around $15 \mathrm{~cm}$; therefore integration in the floor of a vehicle is also an option. In the most recent estimates the FPLG with a central opposed piston combustion unit (explained in the next section) and all auxiliaries can achieve a volumetric power density of up to 470 $\mathrm{W} / \mathrm{l}$ at $50 \mathrm{~Hz}$. [4] As shown in [6] the frequency is dependent on the moving mass. To achieve $50 \mathrm{~Hz}$, the moving mass of the FPLG module has to be about $4-5 \mathrm{~kg}$.

The NVH behaviour of the FPLG is aimed to be low. As described above each system consists of two modules. By synchronizing these all free inertial mass forces are eliminated. Therefore no vibrations are transferred to the vehicle body. Only the turbocharger and exhaust need standard soundproofing.

The measured break thermal efficiency is higher than 39\%. The estimations based on simulations show that an opposed piston FPLG will reach a break thermal efficiency $43 \%-47 \%$. These high efficiencies are achieved over a wide power range, which is an important advantage of the FPLG over conventional 4 stroke engines. Conventional engines only have a small operating range with high efficiency.

\section{CHALLENGE AND SOLUTION}

An FPLG system for use as electrical power generator would consist of two of the above described modules, to allow for a full mass compensation. Schematic the system could look like figure 2 (a). The most advanced solution is the opposed piston combustion chamber 2 (b).

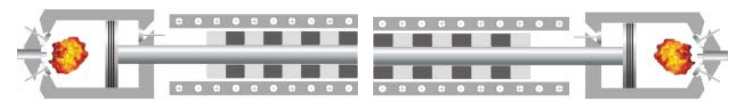

a. dual module system

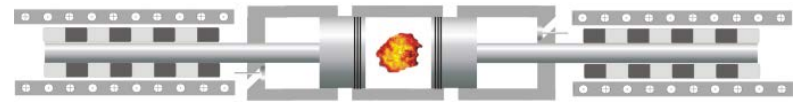

b. opposed piston combustion system

Fig. 2. Free-piston linear generator systems

The opposed piston combustion unit, which is being preferred for the FPLG, has a very simple structure with very little components. It has no cylinder head, the cooling of which is complex. This saves round about $20 \mathrm{~cm}$ in length for each cylinder unit. For scavenging no cam shaft or valves are needed. Additionally the central combustion chamber is easier to scavenge. The valves are replaced by ports opened by the pistons on their way to the bottom dead center. The scavenging takes place while both ports are open. The challenges of this system are the precise port timing, synchronization, scavenging efficiency to mention the most urgent ones.

The main challenge every 2-stroke engine faces is the avoidance of HC emissions. To prevent these emissions the FPLG uses direct injection after all ports are closed. With a stoichiometric combustion a standard three-way catalytic converter can be used. For this purpose the short circuit flow has to be minimized. Otherwise a NOx storage catalytic converter is necessary. The second source of $\mathrm{HC}$ emissions is motor oil. It cools and lubricates the piston which is sliding over the ports letting the oil get into the ports, the combustion 
chamber and exhaust pipe. This increases the HC-emissions. In order to use a central combustion unit this source of HCemissions has to be avoided.

A possible solution which is being developed by the German Aerospace Center (DLR) is to replace motor oil by solid lubricants. This would prevent lubricants getting in touch with the combustion and exhaust. Solid lubricants can be installed in the piston making a complex oil lubrication system obsolete.

\section{DEVELOPMENT METHODOLOGY}

The development starting point is to look at solid lubricated compressors which are in use for quite some time. They use up to seven layers of piston rings made of Teflon materials. There are additional strains the lubrication system has to withstand in order to be used in a combustion chamber. These strains can be divided in three categories:

The combustion develops higher temperatures and pressure gradients than the compressors and their solid lubrication are designed for. To ensure the operation, the right material for the piston rings has to be chosen. This choice will have an impact on other strains and their solutions therefore it is a significant first step. There are many important properties the material has to fulfill in order to be used in a combustion chamber. The most important properties are solid lubrication ability, high bending strength to withstand the pressure, ductility not to break while sliding over the ports and wear resistance and heat resistance. Every material is a compromise partially satisfying the needed requirements. One of the next steps will be to understand the wear and tear of the piston rings in the combustion unit.

The compressors usually do not have any ports to be opened by pistons or rather by piston rings. The valves are usually placed in the cylinder head. The "sliding over the ports” process is a very challenging issue, even for metal rings. Additionally carbon materials show brittle behavior, which can be dangerous in this matter. While sliding over the ports the rings can get stuck, break and damage the machine. To prevent this from happening, the geometry of the rings and ports has to be analyzed. While sliding the piston ring slightly dips into the port. While emerging from the port the ring gets abraded. This increases the wear and tear and in the worst case can lead to a ring fracture. In this matter it is necessary to develop a geometry which prevents the abrading. To do this it is important to know the strains acting on the ring. Next section will show the development process in detail.

The third category is piston cooling. Beside lubrication motor oil is responsible for cooling the piston. In an oil cooled piston $30 \%-70 \%$ of the piston heat is transported by the piston rings, the rest is absorbed by the oil. If the piston runs too hot, the engine starts to knock and the NOx emissions increase. By removing the motor oil a major part of the piston cooling is lost and has to be replaced in some way. Thereby the most important issue is to separate the piston cooling system from the combustion chamber. A piston cooling system is under development and will be published in the future. The plan is to develop a passive cooling system. The goal is to keep the piston temperatures as high as or slightly higher than those of conventional pistons.

\section{GEOMETRY DEVELOPMENT AND RING DESIGN}

In [7] a model for the contact between piston ring and cylinder is described. It shows the important role of the force distribution over the circumference in the developing process of ring design. In consideration of the operational temperature, bending strength and solid lubrication ability carbon materials seem to be the right decision. A few projects exist in which carbon materials were tested but without success in long term operation. [5]

The next step is to choose or develop a first ring design. As mentioned in the section development methodology the starting point is solid lubricated compressors, so this is the source to adopt the first ring design from. A solution which is being developed by the Germany Aerospace center consists of carbon piston rings and carbon guide rings, displayed in the figure 3 . Carbon has brittle behavior, therefore the rings are divided into 3 segments so they can adapt to the surface better.

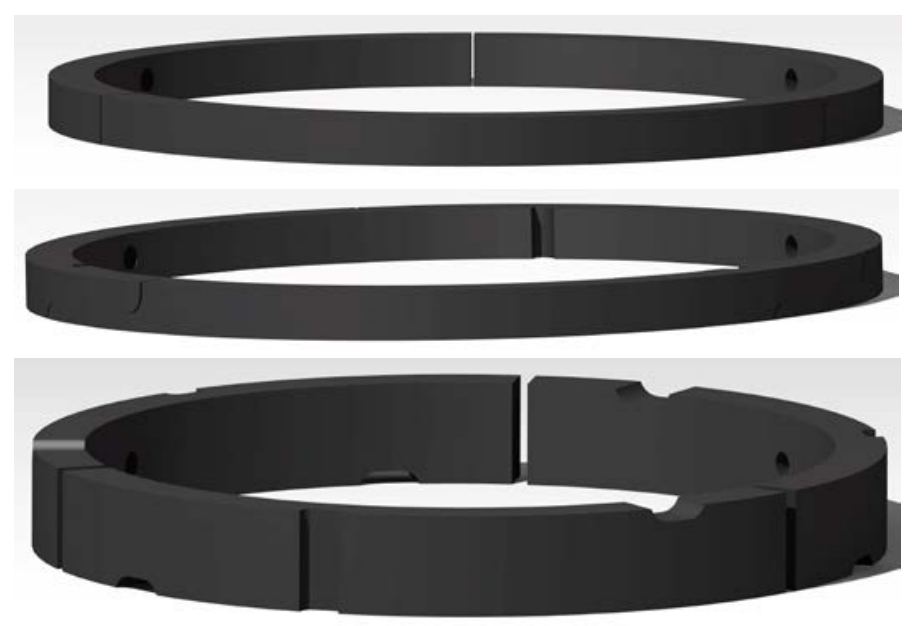

Fig. 3. Pressure ring, sealing ring and a guide ring

The top ring in fig. 3 is a pressure ring. The joint is simple therefore the rings are stable enough to withstand the peak pressure and pressure gradients in the combustion chamber. This ring absorbs the shock through the high pressure gradients and protects the other rings.

The second ring is a so called piston sealing ring. The complex joint is too fragile to withstand the high pressure gradients. It's joint is complex and fragile to maximize the sealing ability as shown in figure 4 .

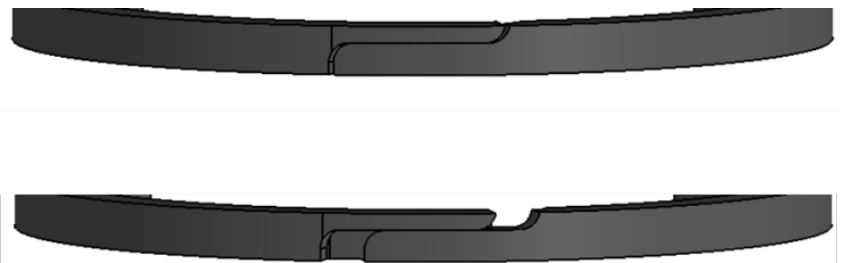

Fig. 4. Joint of a carbon sealing ring 
In the top of figure 4 a new ring with a closed joint is illustrated, below a partially worn out one with a more opened joint is shown for comparison. The joint is "more opened" but still sealed for the blow-by. The ring is $5 \mathrm{~mm}$ thick to compensate the material wear.

The third ring is a guide ring. It keeps the piston equally spaced to the cylinder liner. It is designed for the maximum temperature to ensure that the thermal expansion of all materials do not make the piston stick. As it is not supposed to seal it has axial notches.

The whole ring packet consists of one pressure ring with simple joint, two sealing rings with complex joints and two guide rings which keep the piston in line. This ring packet installed in a piston is shown in the figure 5.

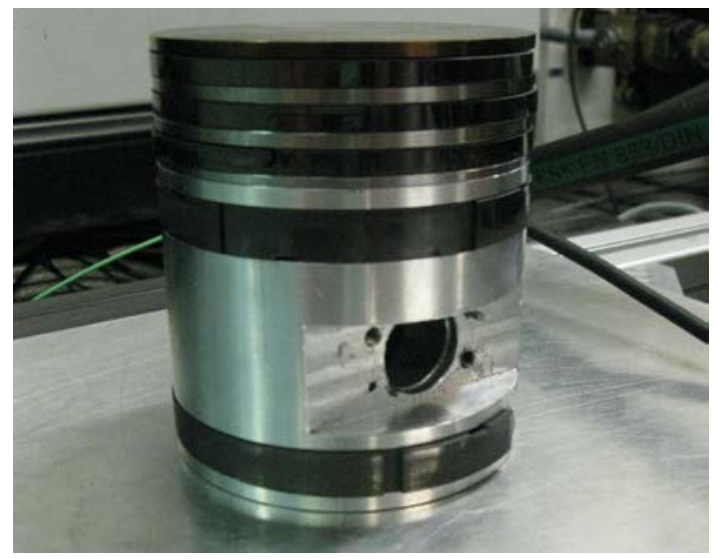

Fig. 5. Piston with carbon ring packet

\section{TEST BENCH}

A test bench was specifically designed and built to test the mechanical properties of the rings. The goal is to test the ports and the lubrication system separately from the other strains. Therefore the tests were performed in a gas spring mode, without combustion. The test bench is shown in the figure 6 below.

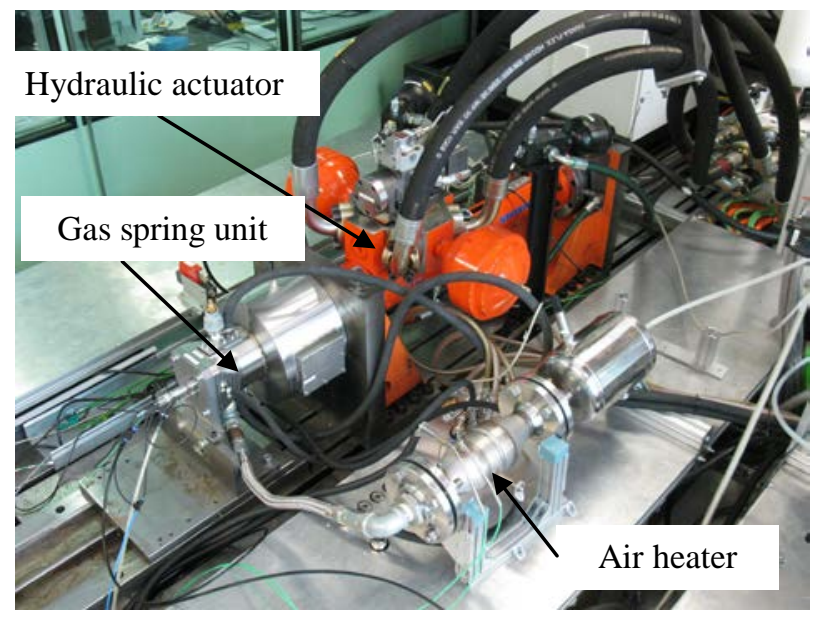

Fig. 6. Test bench for carbon piston rings
The orange hydraulic actuator has a power of $600 \mathrm{~kW}$ and has a flow rate of up to 10001 of hydraulic oil per minute. A gas spring unit (gray) is connected to the actuator. A pressure sensor and a temperature sensor are mounted in the cylinder head. Fresh air is scavenged through ports. Both the cylinder head and the piston are flat to allow for high compression ratios of about 1:20. In the figure 7 a cylinder liner with ports is shown which is used on the test bench. Also the cylinder head with the sensors is visible. Normally the piston rings need an anti-twist protection so their joints do not dip in while sliding over the ports. To keep the piston rings simple the ports are inclined making the anti-twist protection unnecessary.

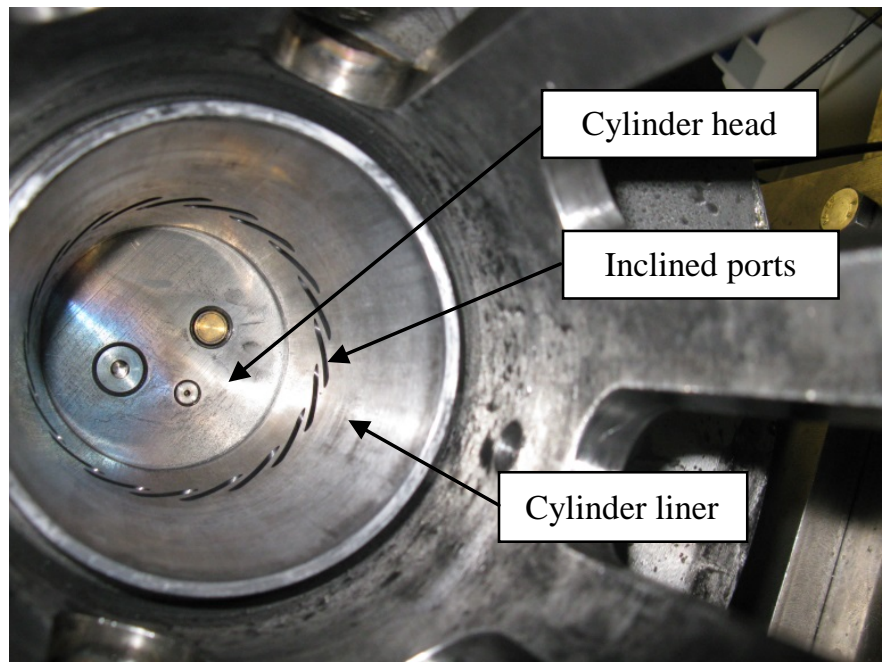

Fig. 7. Cylinder liner with ports in a test bench

\section{RESULTS}

The first test runs were performed to check how the piston rings behave around the ports. Each run lasted for about 6 hours and was performed with $20 \mathrm{~Hz}$, up to 70 bar peak pressure and with a stroke of $80 \mathrm{~mm}$. In this configuration, blowby measurements are not possible. But the blowby is expected to be higher than that of conventional oil lubricated piston rings. The piston temperatures are not measured, because they are expected to be as high as the temperature of the cylinder liner coolant [6]. After each test, the test bench was disassembled and the piston rings examined. Figure 8 shows a new carbon ring before it is set into the test bench. 


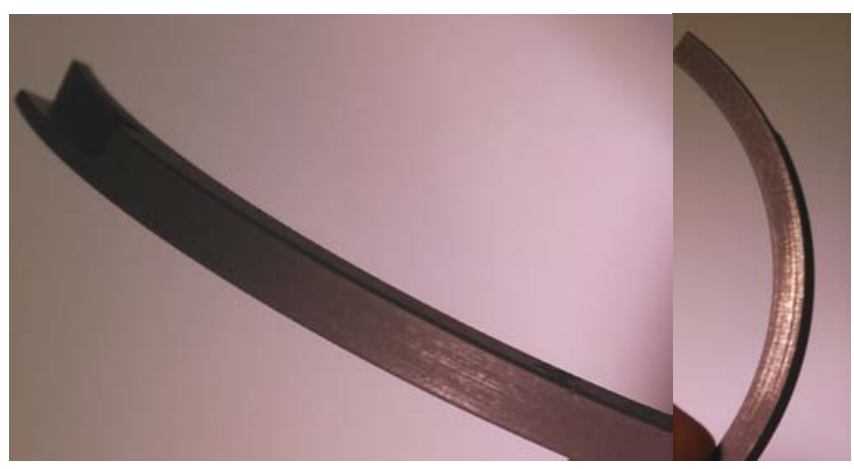

Fig. 8. New carbon ring segment

The color of the new ring is mat. This allows a simple check to find out if the ring works properly. When a carbon surface is being worn it changes from mat to shiny / polished. After the rings are broke in during a test run, the surface of the rings look polished as the figure 9 shows.

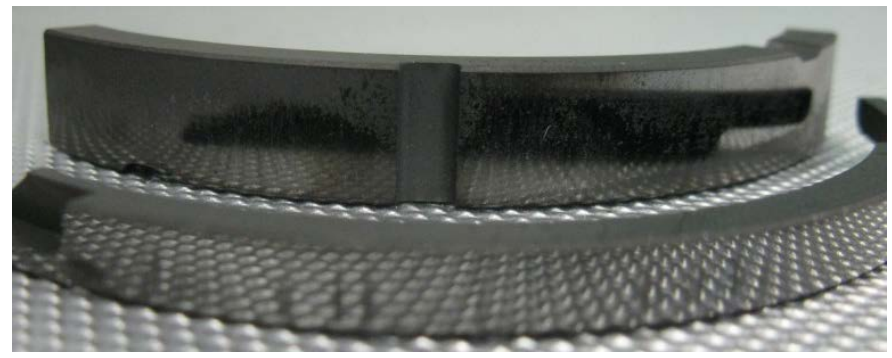

Fig. 9. Used carbon ring segments (From guide ring and pressure ring)

In the figure a segment of a guide ring and of a sealing ring is shown. The whole surface of the segment is shiny, that means the whole ring worked properly and is broke in after less than 6 hours.

However not everything worked perfect in the test runs. $30 \%$ of the rings were broken or chipped. After examining the rings couple of problems were detected.

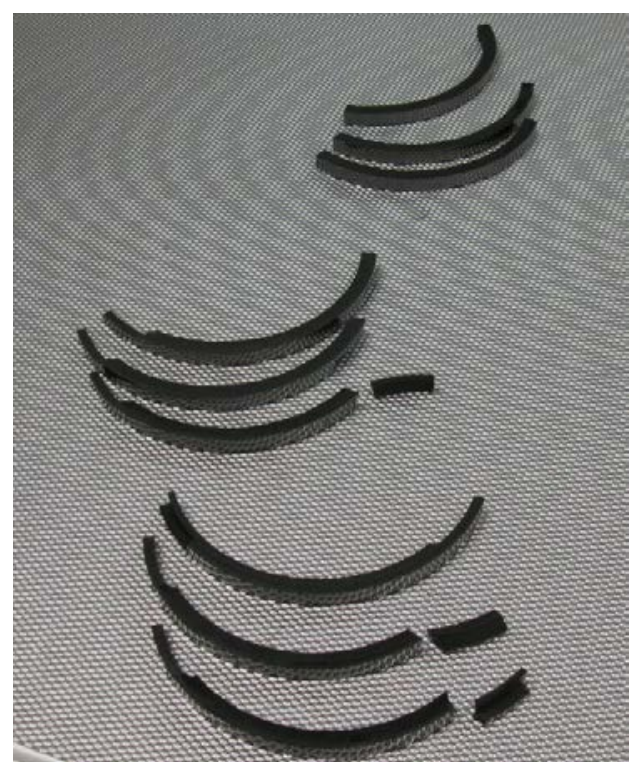

Fig. 10. Broken ring packet

In figure 10 an example of a broken ring packet is shown. The failure after 6 hours has mechanical sources, which will be examined in this section. Most frequently segments of the middle ring, the first sealing ring, broke. The broken parts were the fragile joints of the sealing rings. This ring has two spots with low wall thickness. There were breaks on both spots, but most breaks were on the second thinnest spot as showed in figure 11 .
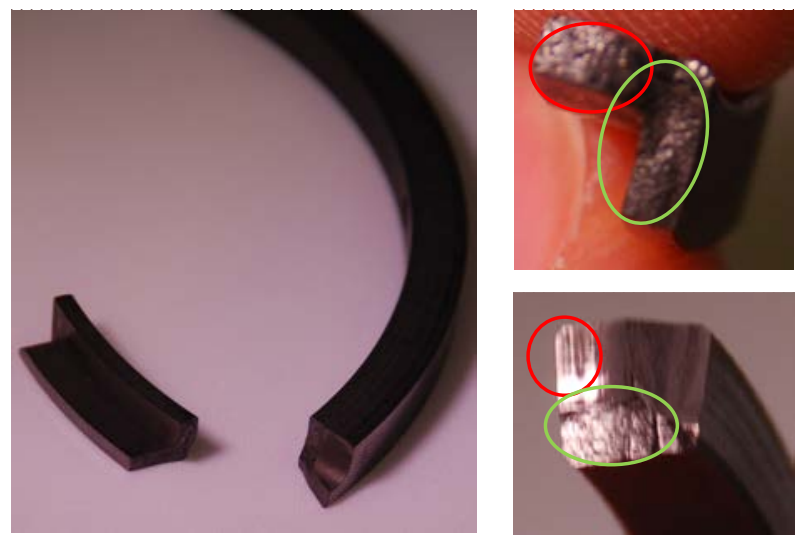

Fig. 11. Broken Sealing ring

The granular surface of the break is shiny, which confirms the brittle behavior of carbon. There are 2 different surface forms in the right photos (Fig 11). The one in the red circle originated from a direct impact, the green one emerged from the following break. 


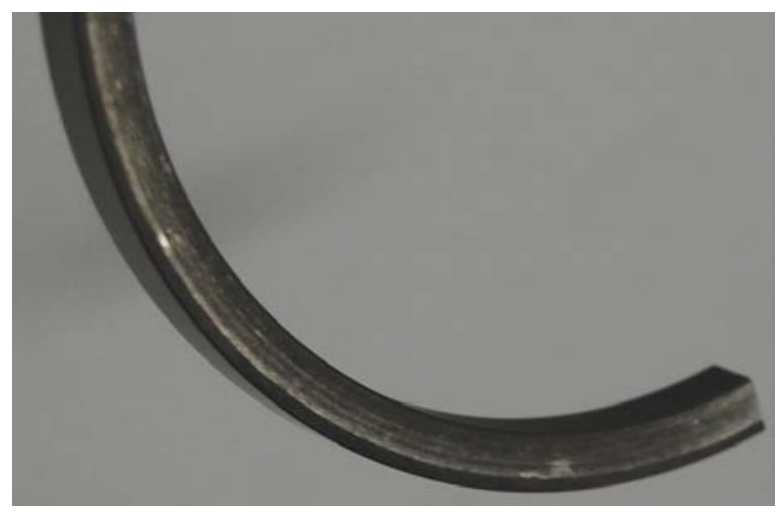

Fig. 12. Ring contact surface

In figure 12 the top surface of the pressure ring consists of a matt black outer part and more or less shiny inner part. The matt black outer part of the surface has no contact to the piston ring notch. The inner part looks more or less shiny/bright, that means it has regular contact to the piston notch.

The guide rings did not experience any damage even though they were in contact with the ports as much as the sealing rings.

The examinations lead to following reasons for the malfunction. The guide rings have thicker walls and a defined position, so the amount of shocks through vibrations while operating is small. The piston rings in comparison have multiple degrees of freedom to adjust their position. They change the contact surface. In this way they experience a series of shocks. To stay in a defined position the pressure and sealing rings need a differential pressure. Around the ports there is no pressure difference, therefore additional shocks occur. The position of the rings around the ports is undefined and they can slightly turn and dip into the ports. This can lead to an immediate breaking of a ring segment.

To prevent these breaks changes in design were made to the piston rings as shown in the figure 13. The rings are more robust and the geometry of the joints was adjusted. The joints are shorter, thicker and the radiuses are larger.

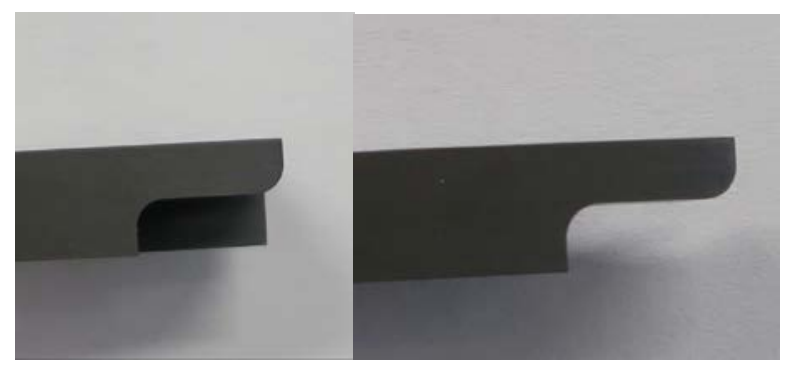

Fig. 13. Second generation of piston rings

The test runs were mostly successful; none of the piston rings broke. As shown in figure 14 the surface looks shiny, that means the piston rings are broke in.

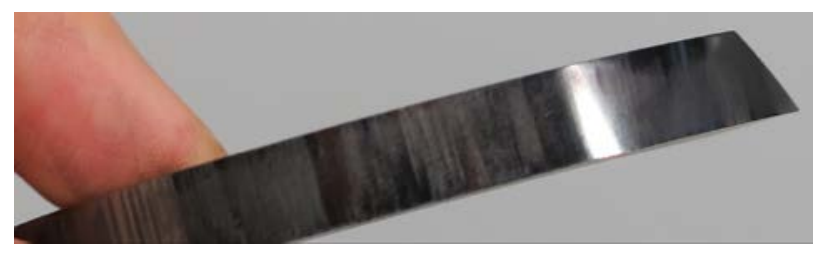

Fig. 14. Piston rings after the test runs

The results show, that the piston rings perform better than the first generation. However the edges of the ring and the corresponding surfaces shown in figure 15 point toward a new problem. Pieces of the ring edge are broke out and scratch the corresponding surface of the ring. The work on the solution is in progress.
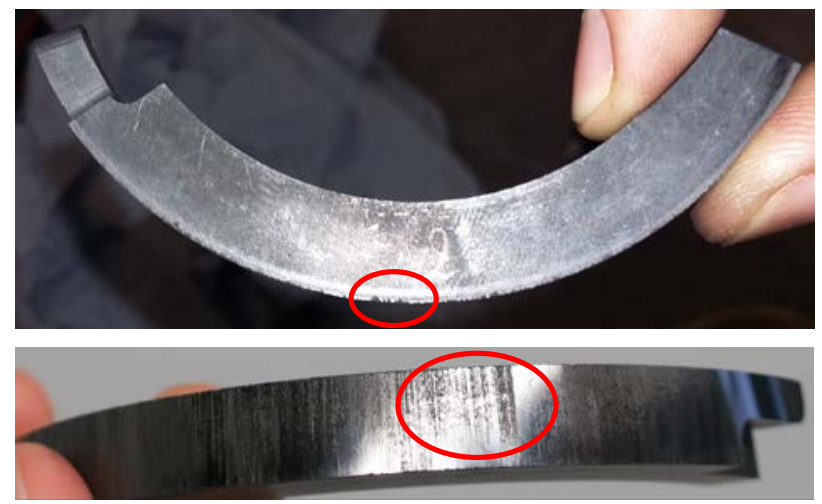

Fig. 15. Piston ring surface

\section{CONCLUSION}

The concept of the free piston linear generator was explained. It consists of three subsystems linear generator, gas spring and combustion section. The characteristic properties of the FPLG were presented together with one of the development challenges. In order to use an opposed combustion chamber the emission issue has to be solved. As an answer one possible solution, solid lubrication, is presented. In this paper the mechanical stresses of the piston rings were closely looked at. The first generation of the rings had some weaknesses, which could to be eliminated. The solid lubrication should be able to withstand the combustion stress after solving the challenges mentioned in the development methodology section.

The FPLG has the potential to be a key component in future drivetrain concepts. Several advantages including improved efficiency are possible. Today's measurement results indicate that the realization of the FPLG within a car may become possible.

[1] B. Metz, O. R. Davidson, P. R. Bosch, R. Dave and L. A. Meyer. "Climate Change 2007: Mitigation of Climate Change". Working Group III to the Fourth Assessment Report of the Intergovernmental Panel on Climate Change IPCC., Cambridge, Cambridge University Press, 2007.

[2] F. Kock, A. Heron, Dr. F. Rinderknecht, Prof. H. E. Friedrich: "THE FREE-PISTON LINEAR GENERATOR POTENTIALS AND CHALLENGES”, 10/2013, MTZ

[3] C. Ferrari "Entwicklung und Untersuchung eines Freikolbenlineargeneratorsystems unter besonderer Berücksichtigung 
des verbrennungsmotorischen Teilsystems mit Hilfe eines neuartigen vollvariablen Prüfstands“, PhD Thesis, German Aerospace Center, 2012.

[4] C. Ferrari, S. Offinger, M.Schier, F.Philipps, et al., "Studie zu Range Extender Konzepten für den Einsatz in einem batterieelektrischen Fahrzeug - REXEL“, DLR, Hacker Media, Stuttgart, 2012

[5] Dipl.-Ing. Gottfried Hilscher, „Der Gegenkolbenmotor verdiente eine Renaissance“, Net Journal, Jahrgang Nr. 14, Heft Nr. 3/4, März/April 2009, www.borderlands.de/net_pdf/net0309s4-8.pdf

[6] S. E. Pohl, „Der Freikolbenlineargenerator - Theoretische Betrachtungen des Gesamtsystems und experimentelle Untersuchungen zum Teilsystem der Gasfeder“, PhD Thesis ,German Aerospace Center, 2007

[7] C. Cheng, A Kharazmi, H. Schock, "THREE DIMENSIONAL PISTON RING-CYLINDER BORE CONTACT MODELING”, ICEF2014-5672, $10 / 2014$ 